\title{
High-Affinity Nicotinic Receptors Modulate Spontaneous Cortical Up States In Vitro
}

\author{
Charalambos Sigalas, Pavlos Rigas, $\odot$ Panagiotis Tsakanikas, and Irini Skaliora \\ Center of Basic Research, Neurophysiology Laboratory, Biomedical Research Foundation of the Academy of Athens, Athens 11527, Greece
}

Nicotinic acetylcholine receptors (nAChRs) play an important role in the modulation of many cognitive functions but their role in integrated network activity remains unclear. This is at least partly because of the complexity of the cholinergic circuitry and the difficulty in comparing results from in vivo studies obtained under diverse experimental conditions and types of anesthetics. Hence the role of nAChRs in the synchronization of cortical activity during slow-wave sleep is still controversial, with some studies showing they are involved in ACh-dependent EEG desynchronization, and others suggesting that this effect is mediated exclusively by muscarinic receptors. Here we use an in vitro model of endogenous network activity, in the form of recurring self-maintained depolarized states (Up states), which allows us to examine the role of high-affinity nAChRs on network dynamics in a simpler form of the cortical microcircuit. We find that mice lacking $\mathrm{nAChRs}$ containing the $\beta 2$-subunit ( $\beta 2$-nAChRs) have longer and more frequent Up states, and that this difference is eliminated when $\beta 2$-nAChRs in wild-type mice are blocked. We further show that endogenously released ACh can modulate Up/Down states through the activation of both $\beta 2$ - and $\alpha 7$-containing nAChRs, but through distinct mechanisms: $\alpha 7$-nAChRs affect only the termination of spontaneous Up states, while $\beta 2$-nAChRs also regulate their generation. Finally we provide evidence that the effects of $\beta 2$-subunit-containing, but not $\alpha 7$-subunit-containing nAChRs, are mediated through $\mathrm{GABA}_{\mathrm{B}}$ receptors. To our knowledge this is the first study documenting direct nicotinic modulation of Up/Down state activity.

Key words: $\beta 2$-nAChR; barrel cortex; cholinergic; network activity; oscillations; persistent activity

Significance Statement

Through our experiments we were able to uncover a clear and previously disputed effect of nicotinic signaling in synchronized activity of neuronal networks of the cortex. We show that both high-affinity receptors (containing the $\beta 2$-subunit, $\beta 2$-nAChRs) and low-affinity receptors (containing the $\alpha 7$-subunit, $\alpha 7$-nAChRs) can regulate cortical network function exhibited in the form of Up/Down states. We further show that the effects of $\beta 2$-nAChRs, but not $\alpha 7$-nAChRs, are mediated through the activation of $\mathrm{GABA}_{\mathrm{B}}$ receptors. These results suggest a possible synthesis of seemingly contradictory results in the literature and could be valuable for informing computational models of cortical function and for guiding the search for therapeutic interventions.

\section{Introduction}

Nicotinic acetylcholine receptors (nAChRs) play an important role in the modulation of cortical processing during cognitive tasks such as attention, learning, and memory. Impairments of the nicotinic circuitry have been associated with disease states such as dementia, depression, and attention deficit disorder (Pic-

Received Dec. 23, 2014; revised May 13, 2015; accepted June 9, 2015.

Author contributions: C.S. and I.S. designed research; C.S. and P.R. performed research; P.T. contributed unpublished reagents/analytic tools; C.S. and P.R. analyzed data; C.S. and I.S. wrote the paper.

This work was supported by EU-FP7 Transmed 245928 and the Marie Curie Re-integration Grant (INTRICA). We thank Professor G.K. Kostopoulos for critical reading of this manuscript and Dr. E. Konsolaki for her contribution in animal care and valuable input on the statistical methods.

The authors declare no competing financial interests.

Correspondence should be addressed to either Irini Skaliora or Charalambos Sigalas, BRFAA, Soranou Efessiou 4, Athens 11527, Greece, E-mail: iskaliora@bioacademy.gr or csigalas@bioacademy.gr.

DOI:10.1523/JNEUROSCI.5222-14.2015

Copyright $\odot 2015$ the authors $\quad 0270-6474 / 15 / 3511196-13 \$ 15.00 / 0$ ciotto and Zoli, 2002; Potter and Newhouse, 2004; Mansvelder et al., 2006) rendering nAChRs a prime target for therapeutic interventions. Because of the complexity of the multiple cholinergic pathways the mechanisms underlying nicotinic modulation in the cortex are still unclear. Receptors come in different varieties, with distinct kinetics and desensitization properties. They are differentially expressed in presynaptic and postsynaptic compartments, in different cortical layers, neuronal types, and subcellular compartments, and can affect network activity through both synaptic and nonsynaptic mechanisms (Dani and Bertrand, 2007; Zaborszky et al., 2012). In addition, ACh can either depolarize or hyperpolarize neurons leading to diverse and contextspecific effects on excitation/inhibition balance. Consequently, although many aspects of nicotinic signaling have been characterized over the years, studies addressing the integration of these different modes of action in functional networks are still scarce. Moreover, it is often difficult to compare and combine results 
from in vivo studies because of the diversity of experimental conditions and the effects of anesthetics on receptor function (Hara and Harris, 2002). For instance, the role of nAChRs in the synchronization of cortical activity during slow-wave sleep is still controversial. Some studies show that nicotinic receptors are involved in ACh-dependent EEG desynchronization-a signature of aroused brain states associated with wakefulness or REM sleep (Yamamoto and Domino, 1965; Armitage et al., 1969; SalinPascual et al., 1999) — while others suggest that the effect is mediated exclusively by muscarinic receptors (Metherate et al., 1992; Steriade et al., 1993; Toth et al., 2012).

One of the most abundant types of nAChRs in the neocortex contains the $\beta 2$-subunit, which forms high-affinity receptors. Genetic manipulations of this subunit have provided indirect evidence that $\beta 2$-nAChRs participate in cortical EEG desynchronization. Mice lacking $\beta 2$-nAChRs exhibit reduced microarousals during NREM sleep (Léna et al., 2004), while mutations that cause receptor hyperactivity lead to increased numbers of micro-arousals (Halász et al., 2013). These studies indicate a regulatory role for $\beta 2$-nAChRs in the transition between synchronized and desynchronized states that has not been explored systematically.

Here we use an in vitro model of cortical network activity in mouse brain slices that spontaneously generate Up/Down states in the absence of pharmacological or electrical stimulation. Several studies have reported that this model approximates slowwave activity during sleep (Sanchez-Vives and McCormick, 2000; Shu et al., 2003; Compte et al., 2008) and have used it to explore cortical network dynamics (Rigas and Castro-Alamancos, 2007; Mann et al., 2009; Fanselow and Connors, 2010). We use $\beta 2$ knock-out mice $\left(\beta 2^{-/-}\right)$and pharmacological experiments to investigate whether $\beta 2-\mathrm{nAChRs}$ participate in the regulation of Up/Down state activity. In addition, given the accelerated aging phenotype exhibited by these mice (Zoli et al., 1999; Konsolaki and Skaliora, 2014), we examine this network phenomenon in both adult and old animals.

\section{Materials and Methods}

Animals. C57BL/6J WT and $\beta 2^{-1-}$ mice were bred in the animal facility of the Center for Experimental Surgery of the Biomedical Research Foundation of the Academy of Athens. The facility is registered as a breeding and experimental facility according to the Presidential Decree of the Greek Democracy 160/91, which harmonizes the Greek national legislation with the European Council Directive 86/609/EEC on the protection of animals used for experimental and other scientific purposes. Mice were weaned at P21, housed in groups of 5-9, in $267 \times 483 \times 203 \mathrm{~mm}$ cages supplied with bedding material, and kept at a $12 \mathrm{~h}$ dark/light schedule. Food was provided ad libitum.

Brain slice preparation. Coronal brain slices $(400 \mu \mathrm{m})$ from the primary somatosensory (S1) cortex of the mouse whisker system (i.e., barrel cortex, S1BF; AP from bregma: $0.58-1.58 \mathrm{~mm}$, ML: $2.5-4 \mathrm{~mm}$ ) were prepared from adult (3-9 months old) and aged (20-27 months old) male mice. After the animal was killed by cervical dislocation the brain was removed and placed in an oxygenated $\left(95 \% \mathrm{O}_{2}-5 \% \mathrm{CO}_{2}\right)$, ice-cold dissection solution containing the following (in $\mathrm{mM}$ ): $2.14 \mathrm{KCl}, 1.47$ $\mathrm{NaH}_{2} \mathrm{PO}_{4} . \mathrm{H}_{2} \mathrm{O}, 27.0 \mathrm{NaHCO}_{3}, 2.2 \mathrm{MgSO}_{4}, 10.0$ D- glucose, 200 sucrose, and $2.0 \mathrm{CaCl}_{2} \cdot 2 \mathrm{H}_{2} \mathrm{O}$, osmolarity (mean $\pm \mathrm{SD}$ ) $298 \pm 5 \mathrm{mOsm}, \mathrm{pH}$ 7.4. Slices were cut using a vibratome (VT 1000S; Leica), placed in a holding chamber with aCSF [containing the following (in $\mathrm{mM}$ ): $126 \mathrm{NaCl}, 3.53$ $\mathrm{KCl}, 1.25 \mathrm{NaH}_{2} \mathrm{PO}_{4} . \mathrm{H}_{2} \mathrm{O}, 26.0 \mathrm{NaHCO}_{3}, 1.0 \mathrm{MgSO}_{4}, 10.0$ D-glucose, and $2.0 \mathrm{CaCl}_{2} \cdot 2 \mathrm{H}_{2}$, osmolarity (mean $\pm \mathrm{SD}$ ) $317 \pm 4$ mOsm, pH 7.4], and left to recover at room temperature $\left(\mathrm{RT} ; 24-26^{\circ} \mathrm{C}\right)$ for at least $1 \mathrm{~h}$ before use.

In vitro electrophysiology. Slices were transferred to a submerged chamber (Luigs \& Neumann), where they were constantly perfused at high flow rates $(10-15 \mathrm{ml} / \mathrm{min})$ to ensure optimal oxygenation of the cortical tissue (Hájos et al., 2009; Ivanov and Zilberter, 2011). Recordings were performed in "in vivo like" aCSF (composition as above but with 1 $\mathrm{mm} \mathrm{CaCl} 2$ ), because this ionic solution is thought to better mimic CSF in vivo (Harris et al., 1984; Jones and Keep, 1988). Recordings were performed at RT, after at least $30 \mathrm{~min}$ of incubation in $1 \mathrm{~mm}\left[\mathrm{CaCl}_{2}\right] \mathrm{aCSF}$. Spontaneous network activity was assessed by means of (1) local field potential (LFP) recordings (sampled at $5 \mathrm{kHz}$ or $10 \mathrm{kHz}$, band-passed filtered at $1-3000 \mathrm{~Hz}$ ) obtained from cortical layers II/III using low impedance $(\sim 0.5 \mathrm{M} \Omega)$ glass pipettes filled with aCSF and (2) visually guided whole-cell patch-clamp recordings from layer II-IV cells with 7-10 M $\Omega$ impedance electrodes. Patch electrodes were filled with a solution containing the following (in $\mathrm{mm}$ ): $135 \mathrm{~K}$-gluconate, $4 \mathrm{KCl}, 2 \mathrm{NaCl}$, 0.2 EGTA, 5 Tris-phosphocreatine, 0.3 Tris-GTP, 10 HEPES, and 4 MgATP (290 mOsm). Intracellular recordings were performed as proof of concept to ensure that the signal we obtained in the LFP recordings corresponded to intracellular Up and Down states and to evaluate the pharmacological response. Only cells with stable membrane voltage and input resistance were used for our assessment. Signals were acquired and amplified (MultiClamp 700B; Molecular Devices), digitized (InstruTech; ITC-18), and viewed on-line with appropriate software (AxoGraph X, version 1.3.5).

Pharmacology. Recordings were also obtained in the presence of (1) the $\beta 2$-nAChR-antagonist, dihydro- $\beta$-erythroidine hydrobromide $(\mathrm{DH} \beta \mathrm{E}$; $3 \mu \mathrm{M}$; Tocris Bioscience) and (2) both $\mathrm{DH} \beta \mathrm{E}$ and the $\alpha 7$-nAChRselective antagonist, methyllycaconitine citrate (MLA; $10 \mathrm{~nm}$; Tocris Bioscience). Although MLA is known to also block $\alpha 6 \beta 2 \mathrm{nAChRs}$ with $\sim 30$-fold lower affinity $\left(K_{i}: 33\right.$ and $1.4 \mathrm{~nm}$, for $\alpha 6 \beta 2$ and $\alpha 7$, respectively), it was added only after $\beta 2$ blockade with $\mathrm{DH} \beta \mathrm{E}$ so that its effect would reveal the $\alpha 7$-mediated component (Klink et al., 2001; Mogg et al., 2002). After recording baseline activity in the absence of any drugs, $\mathrm{DH} \beta \mathrm{E}$ was added to the perfusion medium and the LFP signal was monitored for $30 \mathrm{~min}$. Subsequently, MLA was added to the DH $\beta \mathrm{E}$ containing medium and Up/Down state activity was monitored for another $30 \mathrm{~min}$. In some experiments the same protocol was followed with the exception that the $\mathrm{GABA}_{\mathrm{B}}$ receptor antagonist, CGP55845 (1 $\mu \mathrm{M}$; Tocris Bioscience), was applied $30 \mathrm{~min}$ before $\mathrm{DH} \beta \mathrm{E}$. The AChR agonist carbachol (500 nm; Sigma) was applied in separate experiments.

Data analysis. For visualization and analysis of spontaneous LFP events, traces were exported to MATLAB format. The analysis of each recorded trace was performed with MATLAB scripts that automatically detected the deflections in the LFP trace. These data were first low-pass filtered at $200 \mathrm{~Hz}$ (third-order Butterworth filter) and the DC offset was subtracted. Detection of individual LFP bursts was performed with the following automated method: (1) the signal was transformed using the Hilbert Transform to estimate its envelope (Oppenheim et al., 1999) and (2) a threshold was applied to detect signal segments with fluctuation values larger than $40 \%$ of the SD of the entire signal. This threshold was calculated for each trace (data-driven threshold) to ensure that the detection procedure is adjusted to the corresponding signal-to-noise ratio of each recording and to the specific properties of each time series (e.g., size and frequency of events). Subsequently, the automatically detected LFP events were visually inspected to reject artifacts caused by electrical and/or mechanical noise. Up state duration of each event was calculated as the time interval between the onset and offset of individual events, while Up state occurrence was defined as the number of events divided by the duration of the recording session.

Statistics. All statistical comparisons are based on LFP traces, unless otherwise stated. Data were initially tested for normality and homoscedasticity to explore if the assumptions for ANOVA are satisfied. Data regarding the occurrence of Up states were transformed using the BoxCox transformation (Box and Cox, 1964) to become normally distributed and with equal variance, and parametric tests were performed on the transformed data. Since recordings were obtained from one or more slices from each animal, we first tested for the best-fit model, according to the smallest Akaike Information Criterion, with two fixed effects (independent variables: age and genotype) and two random effects (animal and brain slice). For both dependent variables (Up state duration and occurrence) the best-fit model was the one without random effects, lead- 


\section{B}

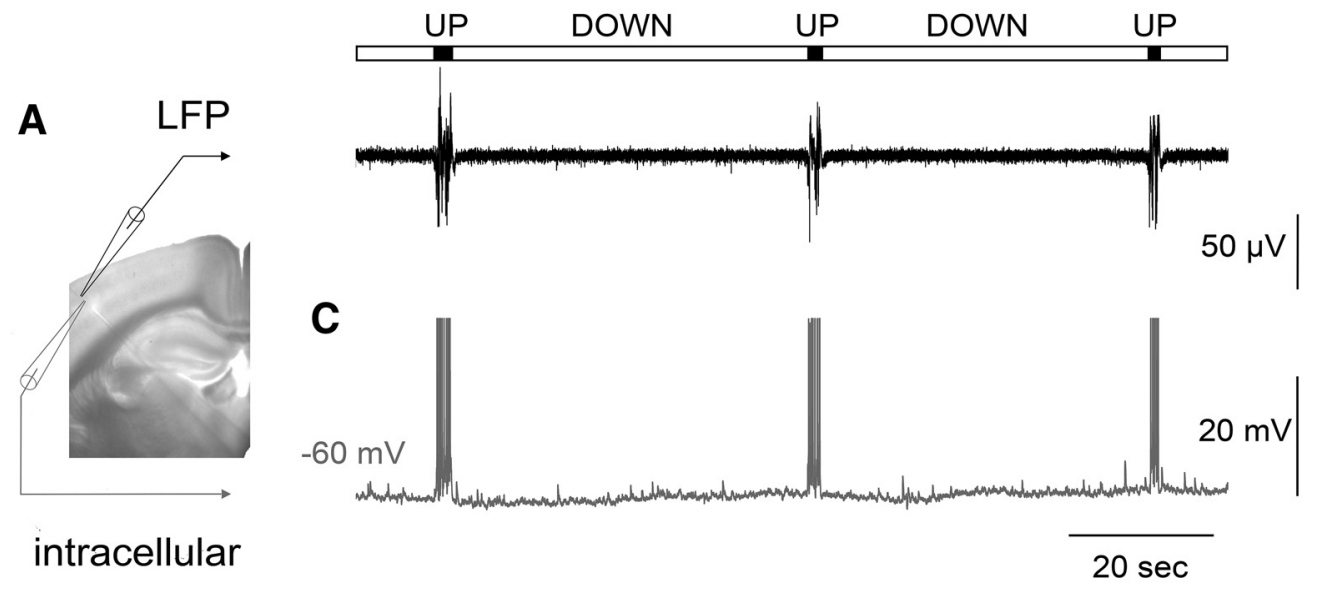

D

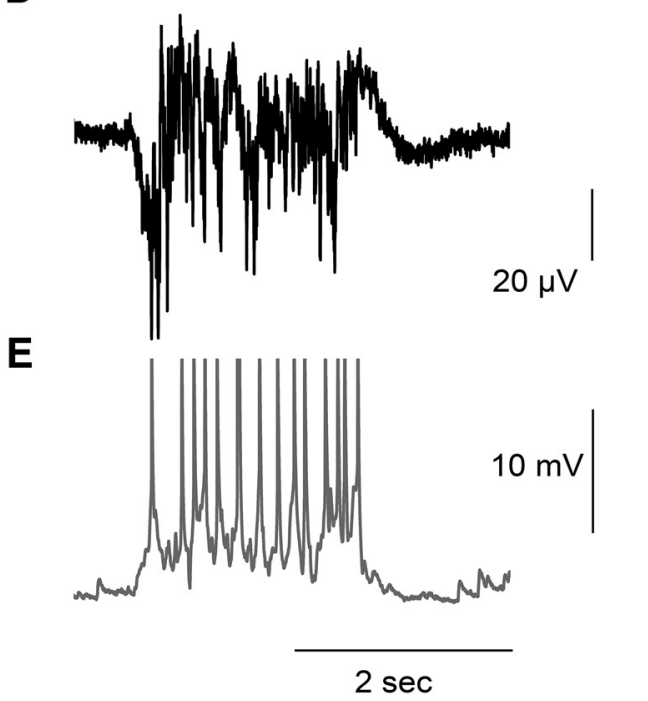

$\mathbf{F}$

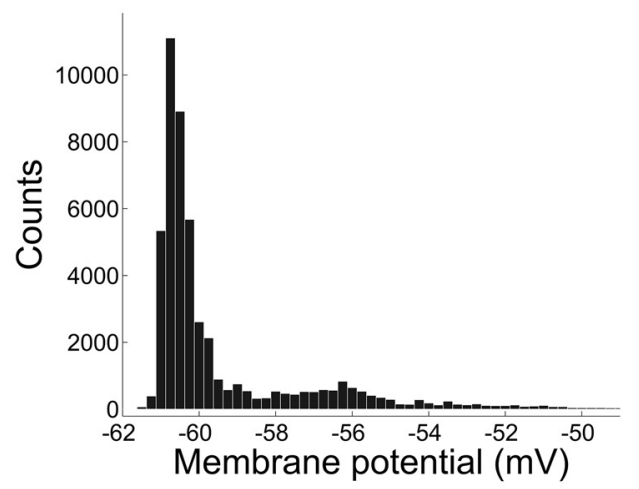

Figure 1. Spontaneous synchronized network activity in the form of Up/Down states recorded in a mouse brain slice. A, Picture of a coronal slice used for simultaneous LFP (black electrode) and intracellular (gray electrode) recording from layer 2/3 of the primary somatosensory cortex. B, C, LFP and intracellular recordings, respectively. The bar above the traces indicates Up states (in black) and Down states (in gray). Action potentials are truncated at $-30 \mathrm{mV} . \boldsymbol{D}, \boldsymbol{E}$, Close-up of the LFP and intracellular recording, respectively, showing an Up state at higher resolution. $\boldsymbol{F}$, Membrane potential distribution with two peaks reflecting the bistable fluctuations of membrane potential during spontaneous network activity.

ing to $p$ values identical to those of a two-way ANOVA using the same statistical hypothesis testing. For the pharmacological experiments we performed a repeated-measures three-way ANOVA with one withinsubjects factor [variable drug with three levels: (1) control, (2) DH $\beta \mathrm{E}$, and (3) $\mathrm{DH} \beta \mathrm{E}+\mathrm{MLA}]$ and two between-subjects factors (variables genotype and age), unless otherwise stated. In cases where there was no statistically significant triple interaction, the effect of the drug was estimated with a repeated-measures two-way ANOVA for each of the between-subjects factors (i.e., variables genotype or age). Double interactions were further investigated using post hoc pairwise comparisons of the within-subjects data (variable drug) with the least significant difference test. The $p$ values reported for the repeated-measures test are corrected for departures from sphericity using the Greenhouse-Geisser estimate of sphericity.

\section{Results}

Cortical slices maintained in vitro spontaneously generate recurring Up and Down states

Recordings were performed in coronal brain slices in which direct (from the basal forebrain) or indirect (through glutamatergic thalamocortical axons) cholinergic axons are cut from their cell bodies to examine intracortical circuits in isolation from subcortically mediated cholinergic modulation. Slices from adult mice exhibited spontaneous network activity characterized by short epochs of sustained LFP events interrupted by longer epochs of relative quiescence (Fig. $1 B, D$ ). Simultaneous intracellular recordings (Fig. $1 C, E$ ) revealed that during the periods of inactivity (the Down state) the cell membrane remained hyperpolarized, while during periods of sustained activity (the Up state) the cells became depolarized with occasional firing of action potentials (average rate: $4.33 \pm 3.35$ spikes per event, $n=72$ ). This bistability of membrane potential $\left(V_{\mathrm{m}}\right)$ is reflected by two peaks in the histogram of $V_{\mathrm{m}}$ distributions (Fig. $1 F$ ). In line with previous work (Shu et al., 2003), the interspike interval during the Up state was highly variable compared with the regular spiking activity produced in the same neurons in response to current injection (data not shown), while the variance of membrane potential was significantly larger $(5.58 \pm 3.18 \mathrm{mV})$ compared with the Down state $(0.3 \pm 0.18 \mathrm{mV} ; n=72)$. Up state duration (ranging between 0.5 and $1.98 \mathrm{~s}$ ) was comparable to in vivo recordings 

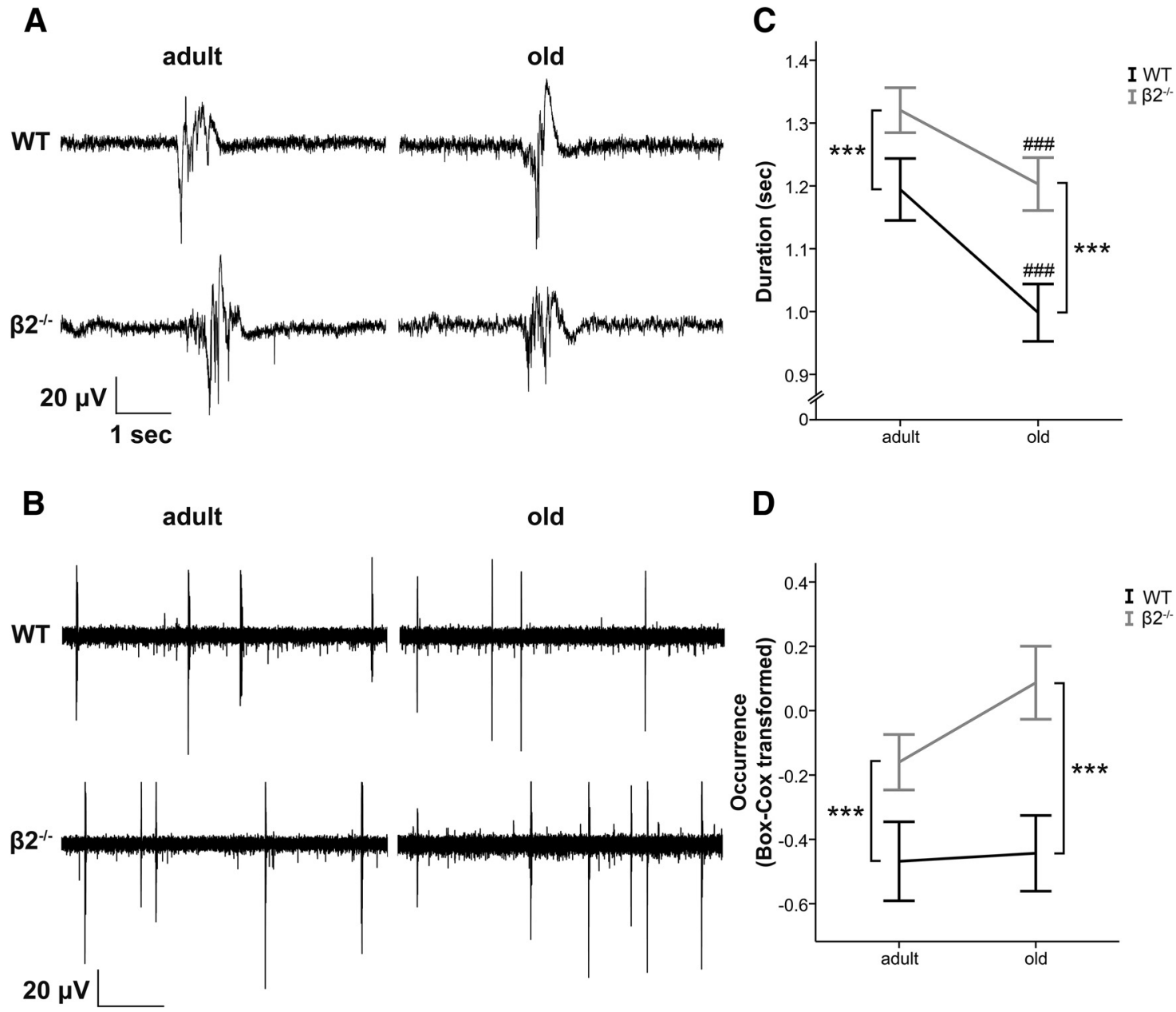

$1 \mathrm{~min}$

Figure 2. Up state activity is enhanced in $\beta 2^{-1-}$ mice. $\boldsymbol{A}, \boldsymbol{B}$, LFP traces (at higher and lower temporal resolution, respectively) obtained from adult (left) and old (right) animals of both genotypes. $\boldsymbol{C}, \mathbf{D}, \beta 2^{-1-}$ mice (gray lines) exhibit increased Up state duration and occurrence (Box-Cox transformed for normality) compared with age-matched WT mice (black lines). Graphs show mean \pm SEM. Asterisk indicates genotype differences, while \# indicates age differences (two-way ANOVA, ${ }^{* * *} p<0.001$ or ${ }^{\# \# \# ~} p<0.001$ ).

(Sanchez-Vives and McCormick, 2000; Timofeev et al., 2001). In contrast, Up state occurrence (ranging between 0.16 and 4 events/min) was significantly lower, but similar to recordings from isolated cortical slabs in living cats (Timofeev et al., 2001), consistent for preparations that contain a more restricted network.

To establish relations with Up states recorded in vivo we performed pharmacological tests. Blocking AMPA-mediated glutamate transmission $(10 \mu \mathrm{M}$ of the ionotropic receptor antagonist CNQX) completely abolished the Up states, while blocking $\mathrm{GABA}_{\mathrm{A}}$-mediated transmission (500 nM gabazine or $1 \mu \mathrm{M}$ bicuculline) transformed the spontaneous events to seizure-like activity (data not shown). Bath application of the cholinergic agonist carbachol (500 nM) resulted in a complete block of the LFP activity, in line with previous in vivo and in vitro reports (Favero et al., 2012; Toth et al., 2012). These data indicate that adult mouse cortical slices bathed in in vivo-like aCSF generate spontaneous Up states closely resembling (both in properties and in pharmacological profile) those occurring in vivo during NREM sleep or anesthesia (Sanchez-Vives and McCormick, 2000; Shu et al., 2003; Sanchez-Vives et al., 2008).

Spontaneous Up state activity is enhanced in $\beta 2^{-1-}$ mice To assess if high-affinity nAChRs participate in cortical network function, we first examined whether the chronic absence of $\beta 2$ -
nAChRs affects the duration and occurrence of spontaneous Up states. Experiments were performed on both adult (3-9 months old) and old (20-27 months old) animals to test for possible age-dependent effects.

Mice lacking the $\beta 2$-subunit exhibit Up states of increased duration compared with WT mice (Fig. $2 A, C$ ). Statistical analysis did not reveal a significant interaction between genotype and age $\left(F_{(1,150)}=0.815, p=0.368\right)$, whereas there was a significant main effect of genotype $\left(F_{(1,150)}=14.472, p<0.001\right)$ indicating that $\beta 2^{-1-}$ animals had longer Up states and that the effect of the mutation was similar for both ages. There was also a significant main effect of age $\left(F_{(1,150)}=13.007, p<0.001\right)$ indicating that Up states become shorter in old animals, as we have previously shown (Rigas et al., 2011; mean \pm SEM, WT adult: $1.19 \pm 0.05 \mathrm{~s}$, $n=38$; WT old: $1 \pm 0.05 \mathrm{~s}, n=38 ; \beta 2^{-1-}$ adult: $1.32 \pm 0.04 \mathrm{~s}$, $n=38 ; \beta 2^{-1-}$ old: $1.2 \pm 0.04, n=40$ ).

In addition to the longer duration, there was also an increased occurrence of Up states in $\beta 2^{-1-}$ mice (Fig. $2 B, D$ ). Here the distribution of the data showed deviations from normality for most genotype-age groups (Shapiro-Wilk test for each group: $P_{\text {WTadult }}=0.001, P_{\text {WTold }}<0.001, P_{\beta 2}{ }^{-1-}$ adult $=0.247, P_{\beta 2}{ }^{-1-}$ old $=0.015)$ so we used the Box-Cox transformation to obtain a normal distribution (details in Materials and Methods). This enabled us to satisfy the assumptions required to perform statistical 
tests that estimate the interaction between genotype and age. We found that there was no significant interaction between the two variables $\left(F_{(1,150)}=1, p=0.319\right)$, whereas there was a significant main effect of genotype $\left(F_{(1,150)}=14.237, p<0.001\right)$, indicating that $\beta 2^{-1-}$ mice exhibit more frequent Up states compared with WT animals (back-transformed mean \pm SEM, WT adult: $0.62 \pm$ 0.15 events/min, $n=38$; WT old: $0.63 \pm 0.14$ events $/ \mathrm{min}, n=38$; $\beta 2^{-/-}$adult: $0.85 \pm 0.1$ events/min, $n=38 ; \beta 2^{-1-}$ old: $1.1 \pm$ 0.14 events/min, $n=40)$. As we have previously shown, there was no main effect of age on the occurrence of Up states $\left(F_{(1,150)}=\right.$ 1.498, $p=0.223$; Rigas et al., 2011).

These results indicate that the chronic absence of high-affinity nicotinic receptors has a significant impact on both the generation (increased occurrence) and the termination (increased duration) of spontaneous cortical Up states, and that this effect is not differentially modulated by aging.

\section{Inhibition of endogenously active $\beta 2-n A C h R s$ leads to enhanced Up state activity}

Since $\beta 2^{-/-}$mice are conventional knock-out animals where the gene is absent throughout embryonic and postnatal development, it is possible that the observed effect is a result of altered connectivity secondary to the genetic manipulation. Alternatively, the effects could have been a direct consequence of reduced nicotinic transmission. This latter scenario rests on the assumption that endogenous ACh is spontaneously released during network activity in cortical slices, and, hence, pharmacological blockade of $\beta 2$-nAChRs in WT mice would be expected to cause changes similar to those observed in $\beta 2^{-/-}$mice. To distinguish between the two possibilities we recorded spontaneous Up states in both genotypes before and after application of the $\beta 2$-selective antagonist, $\mathrm{DH} \beta \mathrm{E}$. We also tested for possible counterbalancing action from the $\alpha 7$-nAChRs by further adding the $\alpha 7$-nAChR antagonist, MLA, to the $\mathrm{DH} \beta \mathrm{E}$-containing medium (described in more detail below). As before, the experiments were performed in adult and aged mice to examine potential age-related changes in nAChR-mediated activity. The statistical analysis indicated that (1) there was no triple interaction between drug (three levels: control, $\mathrm{DH} \beta \mathrm{E}$, and $\mathrm{DH} \beta \mathrm{E}+\mathrm{MLA})$, age, and genotype on either parameter (duration: $F_{(2,62)}=0.452, p=0.6$; occurrence: $\left.F_{(2,62)}=1.628, p=0.21\right)$ and (2) there was also no double interaction between age and drug on either parameter (duration: $F_{(2,62)}=0.052, p=0.922$; occurrence: $F_{(2,62)}=1.183$, $p=0.305)$. Thus, the data from adult and old animals in each group were pooled together for demonstration purposes.

We find that application of the $\beta 2$ antagonist leads to an increase in Up state activity in WT animals (Fig. 3). There was a significant interaction between drug and genotype for both parameters (duration: $F_{(2,62)}=4.439, p=0.023$; occurrence: $F_{(2,62)}$ $=9.186, p<0.001)$, indicating that the drug application has distinct effects on the two genotypes (Fig. $4 A, B$ ). Further analysis with post hoc pairwise comparisons for each genotype group demonstrated that $\mathrm{DH} \beta \mathrm{E}$ significantly increased both the duration $(p=0.012)$ and the occurrence $(p<0.001)$ of Up states in the WT group only. As expected, there was no effect on either Up state duration $(p=0.697)$ or occurrence $(p=0.813)$ of $\beta 2^{-/-}$ mice $\left(n_{\mathrm{WTadult}}=11, n_{\beta 2}{ }^{-1-}\right.$ adult $=10, n_{\mathrm{WTold}}=6, n_{\beta 2}{ }^{-1-}$ old $=$ $8)$, indicating that $\mathrm{DH} \beta \mathrm{E}$ acts exclusively on $\beta 2-\mathrm{nAChRs}$ and is not associated with nonspecific effects on Up/Down state activity.

Notably, blocking $\beta 2$-nAChRs in WT animals had similar effects on Up state activity as those observed in mutant mice, suggesting that $\beta 2$-antagonism can accurately mimic the effect of the genetic deletion and that no significant compensatory effects take place, at least in the context of this network function. These results indicate that $\mathrm{ACh}$ is endogenously released in spontaneously active cortical slices and directly modulates both the generation and termination of Up states through activation of $\beta 2-n A C h R s$.

\section{Inhibition of $\alpha 7-n A C h R s$ can also modify spontaneous network activity}

Our findings of a clear modulatory role of the high-affinity $\beta 2$ $\mathrm{nAChRs}$ on Up/Down states appear in conflict with certain in vivo and in vitro studies that have failed to find an effect of nicotine on this type of activity (Favero et al., 2012; Toth et al., 2012). We reasoned that the discrepancy could be from an opposite action of the other major class of nicotinic receptors in the cortex, the lower affinity $\alpha 7$-nAChRs, which could have masked the effect of $\beta 2$-nAChRs by producing a zero net change in Up state activity after nicotine application. To test for this possibility we compared Up states recorded in the presence of DH $\beta \mathrm{E}+$ MLA (hence blocking both $\beta 2$-nAChRs and $\alpha 7$-nAChRs) to those recorded under control conditions. If the $\alpha 7$-nAChR-mediated effect was opposing the $\beta 2$-nAChR-mediated effect then the activity recorded in WT animals under both antagonists should not be significantly different from the control condition. Instead, our data showed that both Up state occurrence and duration increased in the presence of the two antagonists (post hoc pairwise comparisons, WT, duration: $p=0.001$, occurrence: $p<$ 0.001 ; Fig. $4 C, D)$, indicating that the $\alpha 7$ component is not counteracting the effects of $\beta 2$-nAChRs. In addition, this experiment revealed that blocking $\alpha 7$-nAChRs in $\beta 2^{-1-}$ leads to a modest but significant further increase of Up state duration (post hoc pairwise comparisons, $\beta 2^{-/-}, p=0.035$; Fig. $4 C$ ) but not occurrence $(p=0.260$; Fig. $4 D)$, suggesting that different components of the nicotinic pathway could have distinct effects on spontaneous Up states. This unanticipated finding prompted us to examine whether the same was true in WT mice. We therefore compared Up state characteristics in the presence of $\mathrm{DH} \beta \mathrm{E}+$ MLA with those in the presence of $\mathrm{DH} \beta \mathrm{E}$ alone. This approach allowed us to estimate in the same slices the effect of $\alpha 7$ inhibition: bath application of both antagonists compared with $\mathrm{DH} \beta \mathrm{E}$ increased Up state duration in both genotype groups (post hoc pairwise comparisons, WT: $\left.p=0.022 ; \beta 2^{-/-}: p=0.005\right)$. In contrast, there was no change on Up state occurrence for either genotype (WT: $p=0.190 ; \beta 2^{-l-}: p=0.112 ; n_{\text {WTadult }}=11$, $n_{\beta 2}{ }^{-l-}$ adult $=10, n_{\mathrm{WTold}}=6, n_{\beta 2}{ }^{-1-}$ old $\left.=8\right)$. These results revealed that inhibition of $\alpha 7$-nAChRs had a small but significant additional effect on the duration, but not on the occurrence of Up states, in both WT and mutant mice (Fig. $4 E, F$ ) and demonstrate that the addition of MLA did not cause a counterbalancing effect on Up state activity.

Finally, to examine whether the magnitude of this response is different between the two genotypes, we performed an additional three-way ANOVA that included only the last two levels of the variable drug (i.e., $\mathrm{DH} \beta \mathrm{E}$ and $\mathrm{DH} \beta \mathrm{E}+\mathrm{MLA})$. This analysis showed that there were no triple or double interaction effects for Up state duration (drug, genotype, and age interaction: $F_{(1,31)}=$ $0.502, p=0.484$; drug and genotype interaction: $F_{(1,31)}=0.523$, $p=0.475)$, while there was a significant main effect of drug $\left(F_{(1,31)}=16.947, p<0.001\right)$. Therefore, blocking $\alpha 7$-nAChRs produces similar changes in both genotype groups, suggesting a lack of functional upregulation of $\alpha 7$-nAChRs in mutant animals as a result of the genetic ablation of high-affinity nicotinic receptors, consistent with previously published anatomical findings (Zoli et al., 1998). 
A
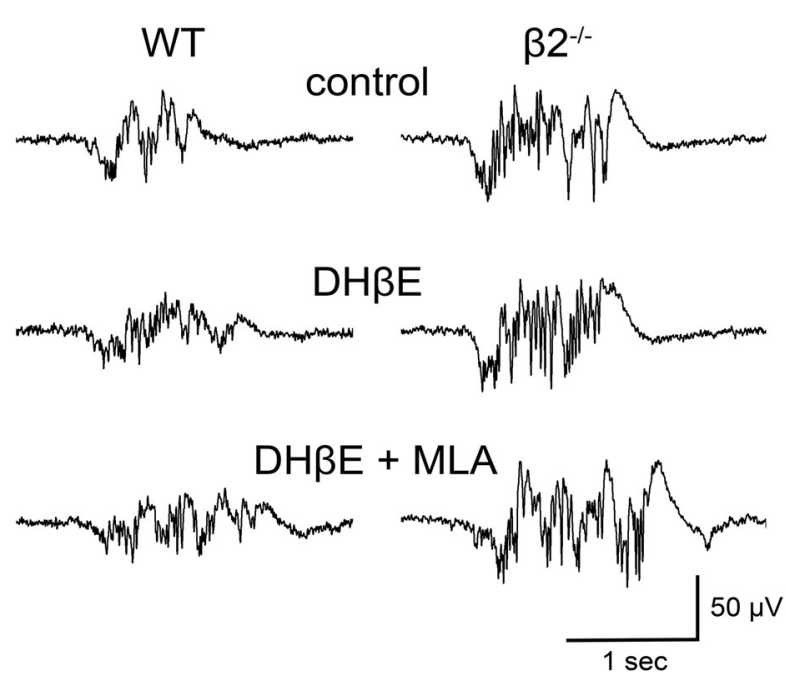

C

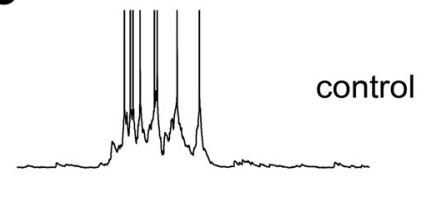

$\mathrm{DH} \beta \mathrm{E}$

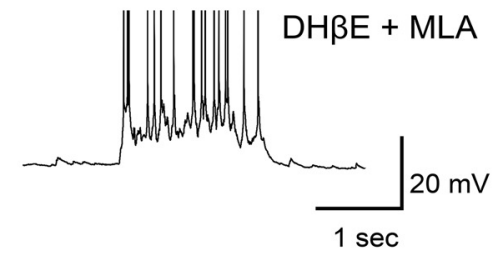

$\beta 2^{-1-}$
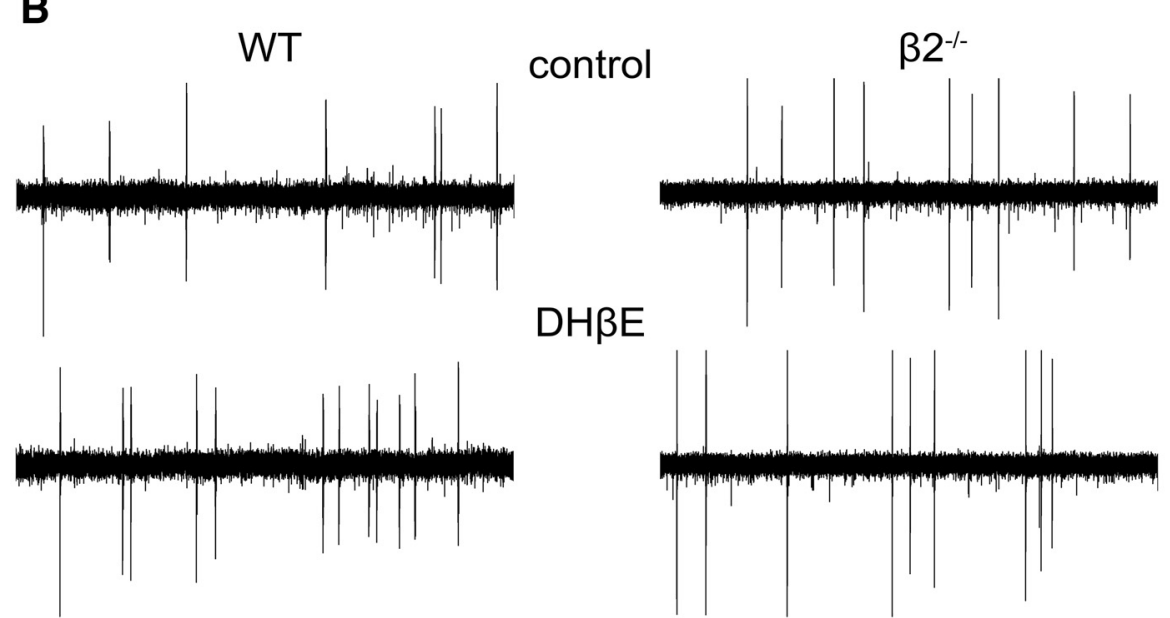

$D H \beta E+M L A$
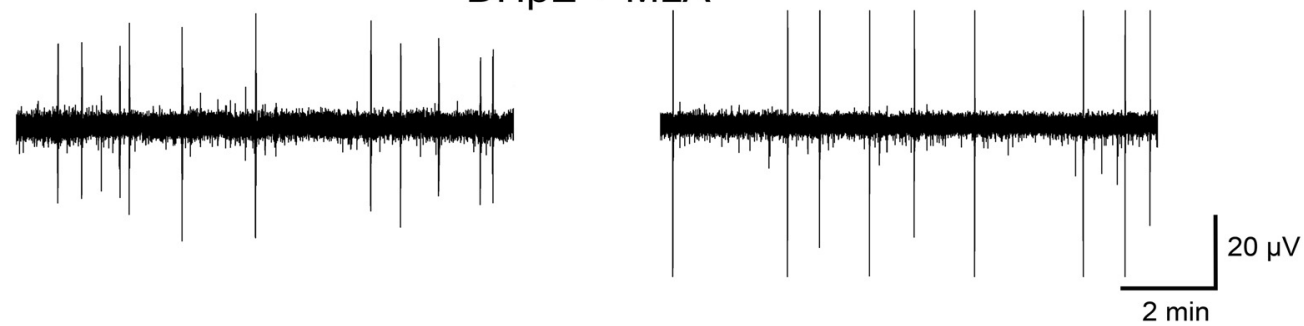

Figure 3. Application of the $\beta 2$-nAChR antagonist $\mathrm{DH} \beta$ E increases Up state duration and occurrence, and subsequent addition of the $\alpha 7$-nAChRs antagonist MLA causes further prolongation of Up state duration. $A, B$, LFP traces of Up state activity at higher and lower temporal resolution, respectively, and $(\boldsymbol{C})$ intracellular recordings obtained in control conditions in the absence of drugs (top), in the presence of $3 \mu \mathrm{m} \mathrm{DH} \beta E$ (middle), and in the presence of $3 \mu \mathrm{m} \mathrm{DH} \beta E+10 \mathrm{~nm} \mathrm{MLA} \mathrm{(bottom).} \mathrm{LFP} \mathrm{traces} \mathrm{in} \boldsymbol{A}$ and $\boldsymbol{B}$ are from WT (left) and $\beta 2^{-1-}$ (right) mice. Traces from intracellular recordings are truncated at $-25 \mathrm{mV}$.

Nicotine application decreases spontaneous network activity Our results documenting the involvement of nAChRs in spontaneous activity are at odds with recently published work examining the same network phenomenon in thalamocortical (TC) slices, according to which exogenous application of nicotine had no effect on Up state activity (Favero et al., 2012). Thus, we next explored whether this discrepancy was because of experimental differences, or, instead, reflected a distinct mechanism of action between endogenous and exogenous activation of nAChRs.

Following a $30 \mathrm{~min}$ baseline recording, WT slices were perfused with a solution containing $10 \mu \mathrm{M}$ nicotine, as in Favero et al. (2012). Similarly to their data on TC slices we found that this dose of nicotine had no effect on Up state duration $\left(t_{(6)}=\right.$ $1.962, p=0.097)$ or occurrence $\left(t_{(6)}=0.626, p=0.554 ; n=\right.$ 7; paired $t$ test; Fig. $5 \mathrm{~A}, C$ ). This suggests that the modulation of network activity by exogenous stimulation of nAChRs is similar in the two studies, despite experimental differences. However, given the effects of $\beta 2$ and $\alpha 7$ antagonists described above, we would have expected a decrease in Up state occurrence and duration in response to application of nicotine. We hypothesized that this inconsistency could be from the very high dose of nicotine $(10 \mu \mathrm{M})$, which could cause rapid desensitization of the nAChRs (Dani and Bertrand, 2007). Hence, we relied on a previous study that demonstrated that intrave- 
nously supplied nicotine caused desynchronization of EEG activity in sleeping cats (Yamamoto and Domino, 1965) and estimated that the supplied nicotine ranged between 500 and $600 \mathrm{~nm}$ (estimation performed for maximum nicotine concentration in plasma calculated by $0.005 \mathrm{mg} / \mathrm{kg}$ nicotine supplied intravenously and assuming cat blood volume ranging between 50 and $66 \mathrm{ml} / \mathrm{kg}$ ). Indeed, when we repeated the above experiment with a lower dose of nicotine (300 nM) we found that both Up state duration $\left(t_{(6)}=4.555, p=0.004\right)$ and occurrence $\left(t_{(6)}=3.296, p=0.016 ; n=\right.$ 7 ) were significantly reduced in the presence of the drug (Fig. $5 B, D$ ). Hence, these results are in line with those obtained by the application of nicotinic antagonists, and provide additional confirmation that nAChRs can directly modulate the synchronized activity of local recurrent networks in the cerebral cortex.

\section{The effect of $\boldsymbol{\beta} 2$-nAChRs is mediated through $\mathrm{GABA}_{\mathrm{B}} \mathrm{Rs}$}

Having established a clear and previously questioned effect of nicotinic regulation of endogenous network activity, we next aimed to explore the possible mechanism of this action. Earlier studies in rats and mice have shown that ACh can directly activate a subset of cortical interneurons expressing nAChRs (Porter et al., 1999; Christophe et al., 2002; Gulledge et al., 2007; Arroyo et al., 2012), suggesting that cholinergic activation may modulate inhibition in the cortex through nAChRs. In addition, another study has demonstrated that blockade of $\mathrm{GABA}_{\mathrm{B}} \mathrm{R}$-mediated inhibition leads to a significant increase in spontaneous Up state duration (Mann et al., 2009), very similar in direction and magnitude to the changes we observed with the $\beta 2$-nAChR antagonist. Based on the results from these studies and on our present findings, we formulated a working hypothesis for the $\beta 2$-mediated nicotinic regulation of Up states (Fig. 6). According to this model, the release of endogenous ACh in spontaneously active slices leads to $\beta 2$-nAChR-mediated excitation of cortical interneurons, release of GABA, and reduction of Up state activity through activation of $\mathrm{GABA}_{\mathrm{B}}$ receptors. Following this rationale, the application of the $\beta 2$ antagonist in the presence of $\mathrm{GABA}_{\mathrm{B}} \mathrm{R}$ blockade should fail to cause the $\beta 2$-nAChR-mediated increase in Up state activity.

To test this hypothesis, we monitored spontaneous Up states in brain slices from
A
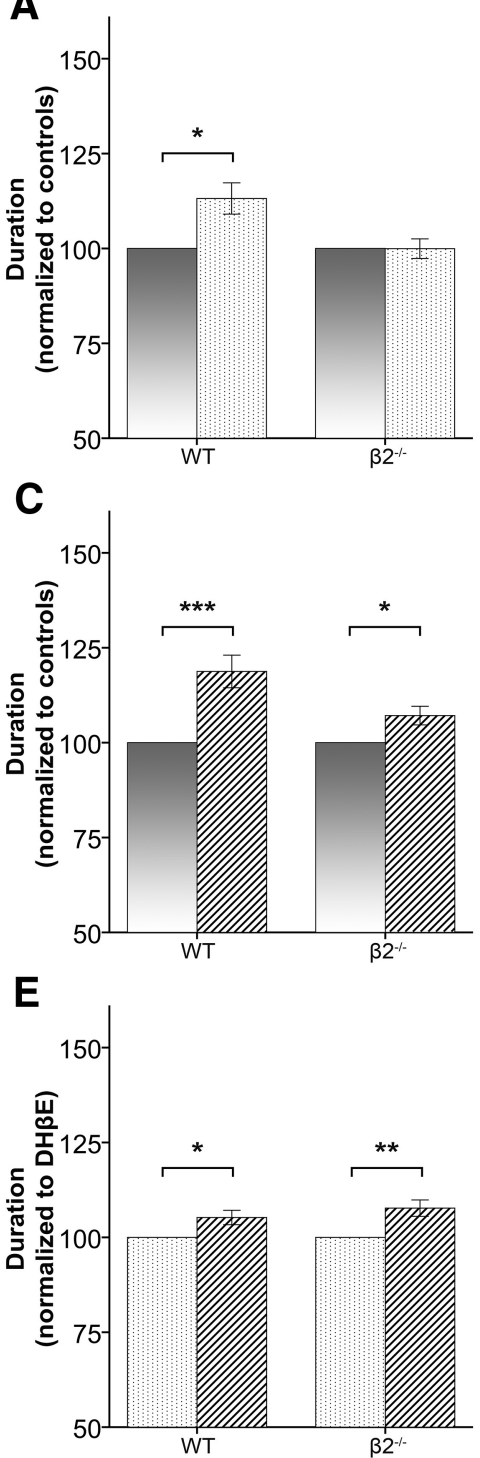

G

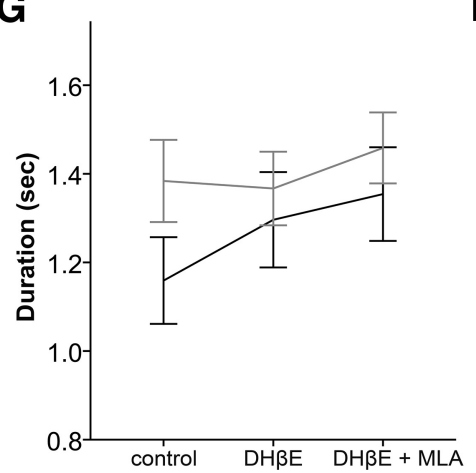

B

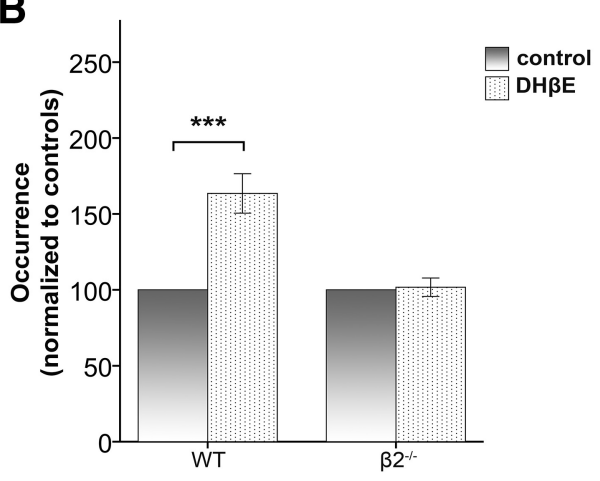

D

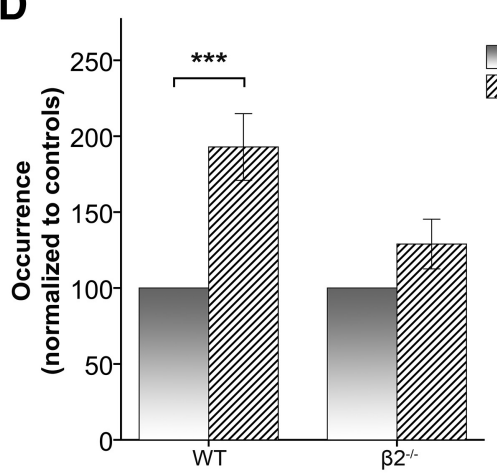

$\mathbf{F}$

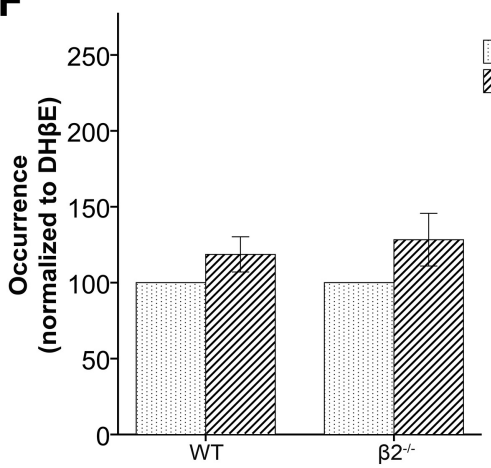

H

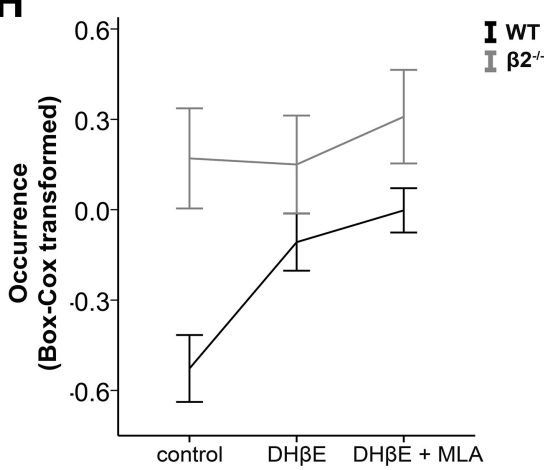

Figure 4. Inhibition of endogenously active $\beta 2-n A C h R s$ and $\alpha 7-n A C h R s$ enhances Up state activity. $\boldsymbol{A}, \boldsymbol{B}$, Up state duration and occurrence, respectively, are increased in the presence of the $\beta 2$-nAChR antagonist $\mathrm{DH} \beta \mathrm{E}(3 \mu \mathrm{M})$ in WT mice only (mean \pm SEM, data normalized to values obtained in the absence of $\mathrm{DH} \beta \mathrm{E})$. C, $\boldsymbol{D}$, The combined effect of $\beta 2$ and $\alpha 7$ inhibition ( $3 \mu \mathrm{m} \mathrm{DH} \beta \mathrm{E}$ and $10 \mathrm{~nm} \mathrm{MLA}$ ) is an increase of both duration and occurrence in WT animals and an increase in duration in $\beta 2$ mutants (mean \pm SEM, data are normalized to the values obtained in the absence of any drug). $\boldsymbol{E}, \boldsymbol{F}$, The $\alpha 7$-nAChRs antagonist MLA (10 nm) causes an additional increase of Up state duration in both WT and $\beta 2^{-1-}$ mice, over and above the effect of DH $\beta E$, but has no significant effect on Up state occurrence (mean \pm SEM, data normalized to values obtained in the presence of DH $\beta E$ ). $\mathbf{G}, \boldsymbol{H}$, Non-normalized values of Up state duration and occurrence, respectively, before and after the addition of DH $\beta E$ and MLA (mean \pm SEM). Black and gray lines indicate WT and $\beta 2^{-1-}$ mice, respectively. Data shown are pooled from both age groups (three-way repeatedmeasures ANOVA, with pairwise comparisons post hoc tests, ${ }^{*} p<0.05,{ }^{* *} p<0.01$, and ${ }^{* * *} p<0.001$ ). 
A

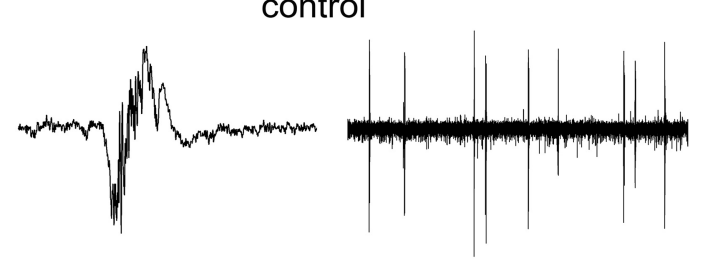

$10 \mu \mathrm{M}$ nicotine

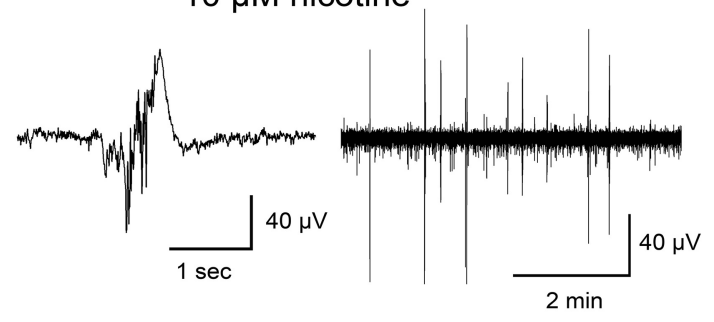

C

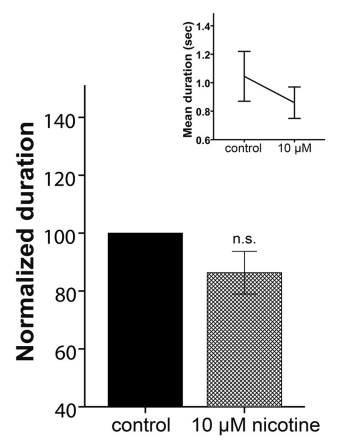

B

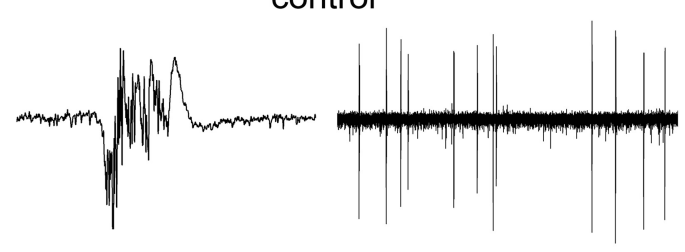

300 nM nicotine

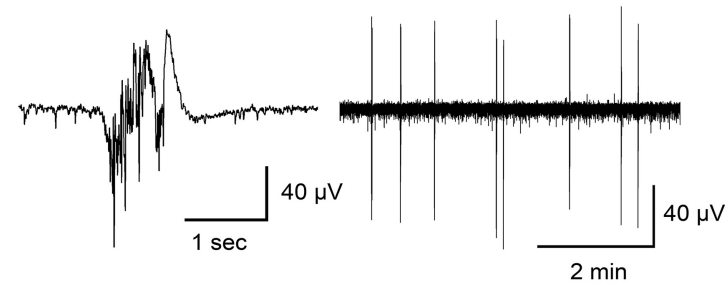

D

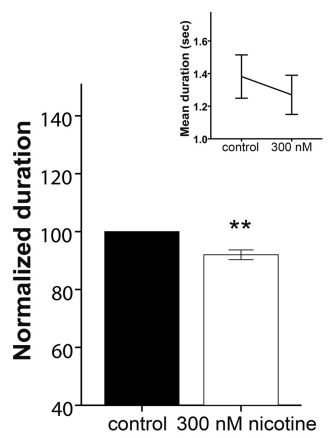

Figure 5. Dose-dependent effect of nicotine on Up state activity in WT mice. LFP traces of Up state activity at higher (left) and lower (right) temporal resolution in the presence of $10 \mu \mathrm{m}(\boldsymbol{A})$ or $300 \mathrm{~nm}(\boldsymbol{B})$ nicotine. C, High concentration of nicotine (10 $\mu \mathrm{m})$ is ineffective in producing significant changes in Up state duration or occurrence. $\boldsymbol{D}$, In contrast, a low concentration of nicotine (300 $\mathrm{nm}$ ) reduces both Up state duration and occurrence. Values in $\boldsymbol{C}$ and $\boldsymbol{D}$ are normalized to controls in the absence of $10 \mu \mathrm{m}$ and $300 \mathrm{~nm}$ nicotine, respectively, while insets demonstrate non-normalized values (mean \pm SEM, paired $t$ tests, ${ }^{* *} p<0.01$ ).

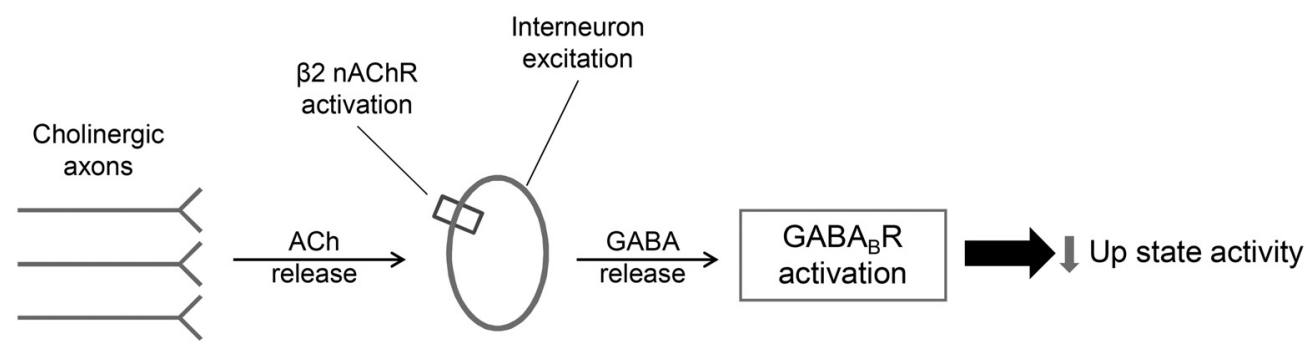

Figure 6. Illustration of working hypothesis: spontaneously active cholinergic fibers release ACh leading to the depolarization of $\beta 2$-nAChR-containing cortical interneurons. The subsequent release of GABA mediates Up/Down state transitions through the activation of $G A B A_{B}$ receptors, leading to reduced Up state activity.

adult WT animals before and after the addition of $1 \mu \mathrm{M}$ CGP55845 in the bathing solution (Fig. 7). Repeated-measures one-way ANOVA (independent variable drug with four levels: control, CGP55845, DH $\beta \mathrm{E}+\mathrm{CGP55845}$, and MLA + DH $\beta \mathrm{E}+$ CGP55845) indicated that there were significant differences among the four conditions for both parameters (duration: $F_{(3,33)}=59.23$, $p<0.001$; occurrence: $\left.F_{(3,33)}=5.173, p=0.025\right)$. In agreement with Mann et al. (2009), further analysis with post hoc pairwise comparisons showed that Up state duration was significantly enhanced $(p<$ $0.001, n=12$ ) in the presence of the $\mathrm{GABA}_{\mathrm{B}} \mathrm{R}$ antagonist (Fig. $8 A$ ). In addition, we also observed a significant increase in Up state occurrence ( $p=0.022$; Fig. $8 B$ ). When we further applied $\mathrm{DH} \beta \mathrm{E}$ in the presence of CGP55845 there was no significant change in either Up state duration $(p=0.536)$ or occurrence $(p=0.627)$, compared with CGP55845 alone (Fig. 8C,D). These results suggest that blocking $\mathrm{GABA}_{\mathrm{B}}$ receptors intercepts the antagonizing effects of $\mathrm{DH} \beta \mathrm{E}$ and are in line with our hypothesis that blocking $\mathrm{GABA}_{\mathrm{B}}$-mediated inhibition prevents the endogenously released $\mathrm{ACh}$ from eliciting its effects on Up state activity.

Finally, we investigated whether the effects of $\alpha 7-n A C h R s$ are also mediated through the $\mathrm{GABA}_{\mathrm{B}} \mathrm{R}$ pathway, by further adding the $\alpha 7$ blocker to the medium already containing $\mathrm{DH} \beta \mathrm{E}$ and CGP55845. In the presence of MLA we observed a significant increase in Up state duration $(p=0.007)$ but not occurrence $(p=$ 0.536; Fig. 8E,F), similar to the effects obtained in the absence of CGP55845 (Fig. 4C,D). Hence, it seems that, unlike $\beta 2$-nAChRs, the 
A

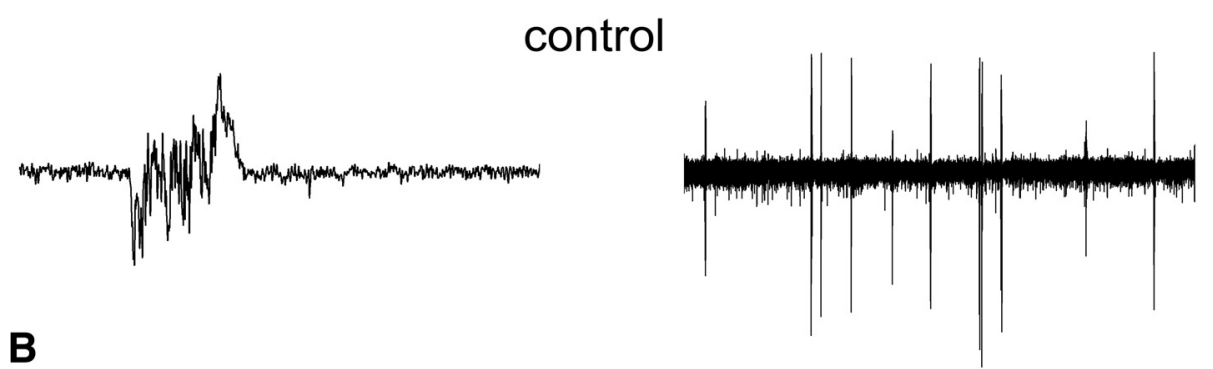

B

CGP55845
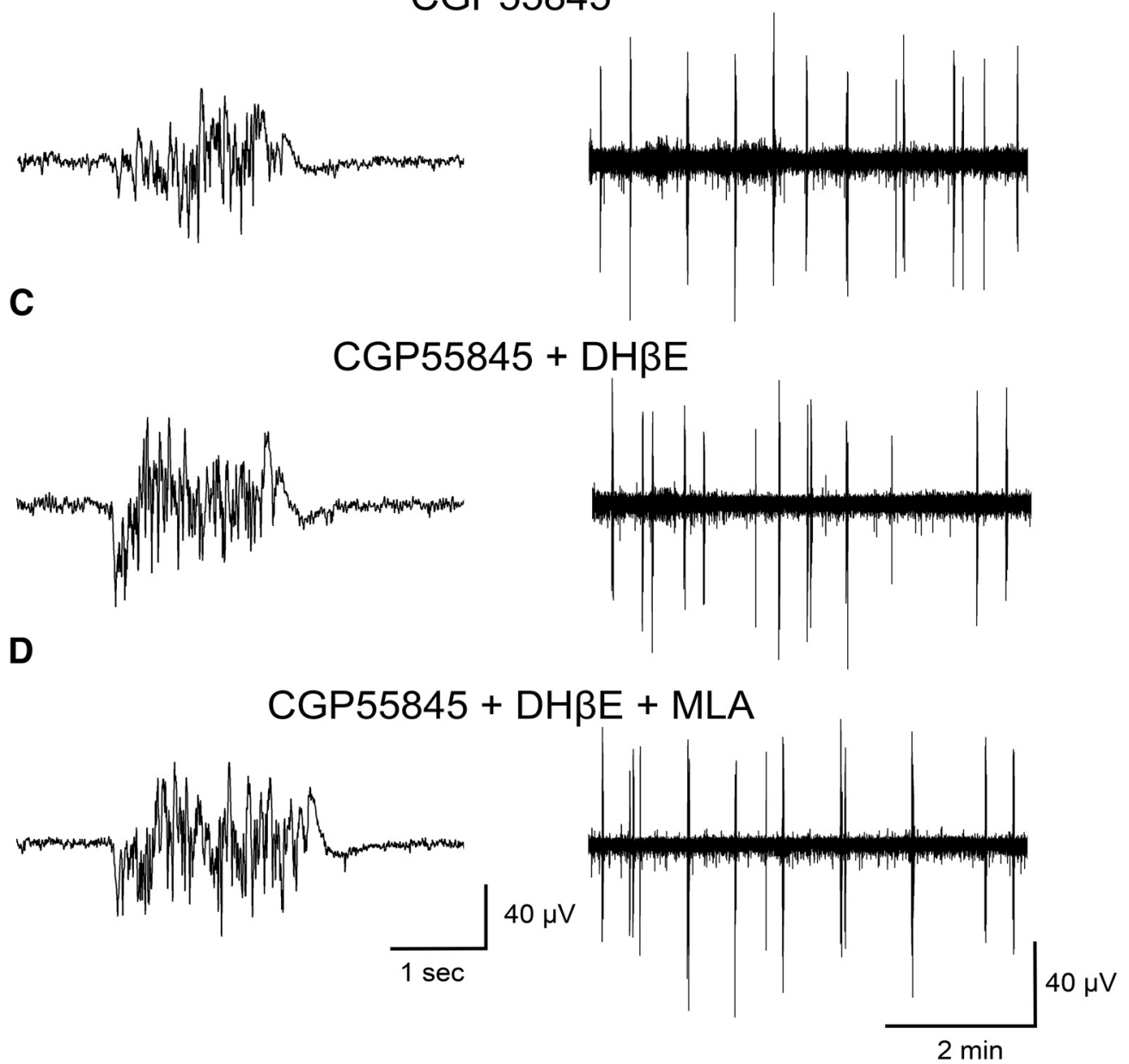

Figure 7. Inhibition of $\mathrm{GABA}_{B}$ receptors eliminates the $\mathrm{DH} \beta \mathrm{E}$-mediated effects on Up state activity. LFP traces of Up state activity at higher (left) and lower (right) temporal resolution from recordings obtained in control conditions in the absence of drugs (A), and in the presence of $1 \mu \mathrm{M}(G \mathrm{PP} 5845(\boldsymbol{B}), 1 \mu \mathrm{M}$ (GP55845 $+3 \mu \mathrm{M} \mathrm{DH} \beta \mathrm{E}(\boldsymbol{C})$, and $1 \mu \mathrm{M} \mathrm{CGP55845}+3 \mu \mathrm{M} \mathrm{DH} \beta \mathrm{E}+10 \mathrm{nM}$ MLA (D).

effects of $\alpha 7$-nAChRs on spontaneous network activity are not mediated by $\mathrm{GABA}_{\mathrm{B}}$ receptors. Moreover, the finding that MLA caused an additional increase in Up state duration demonstrates that CGP55845 does not lead to a ceiling effect in Up state activity, which could have prevented the appearance of any $\mathrm{DH} \beta \mathrm{E}$ effects. These results suggest that blocking the nicotinic effects mediated by $\beta 2$ $n A C h R s$ leads to an increase in both the occurrence and duration of Up states through reduced activation of $\mathrm{GABA}_{\mathrm{B}}$ signaling. In contrast, blocking the $\alpha 7-\mathrm{nAChRs}$ affects only the termination of $\mathrm{Up}$ state activity through a $\mathrm{GABA}_{\mathrm{B}}$-independent mechanism.

\section{Discussion}

Previous studies have reported nAChR-mediated responses in specific types of cortical cells (Alkondon et al., 2000; Lambe et al., 2003;
Poorthuis et al., 2013), but their effect on integrated network function has remained elusive. Here we examined the involvement of high-affinity nAChRs in an in vitro model of spontaneous cortical network activity. Our data reveal that ACh is endogenously released in spontaneously active slices and can modulate the transition between Up/Down states through the activation of nAChRs. We further show that the effects of $\beta 2$-subunit-containing $n A C h R s$, but not $\alpha 7$-subunit-containing nAChRs, are mediated through $\mathrm{GABA}_{\mathrm{B}}$ receptors. To our knowledge this is the first study documenting nicotinic modulation of Up/Down state activity.

\section{Endogenous release of ACh in cortical slices}

The effect of cholinergic blockers on Up state activity strongly suggests that $\mathrm{ACh}$ is endogenously released from cellular 
A

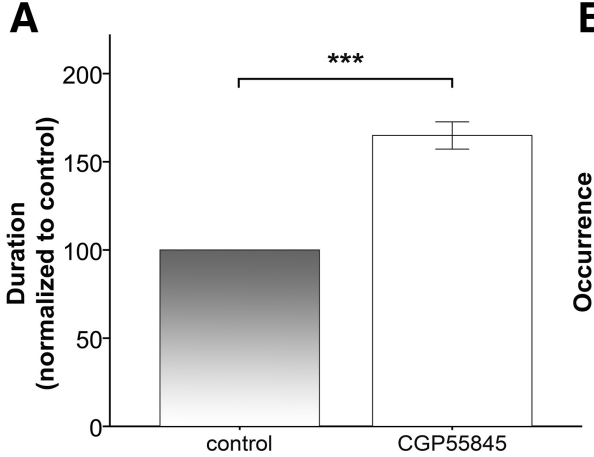

B

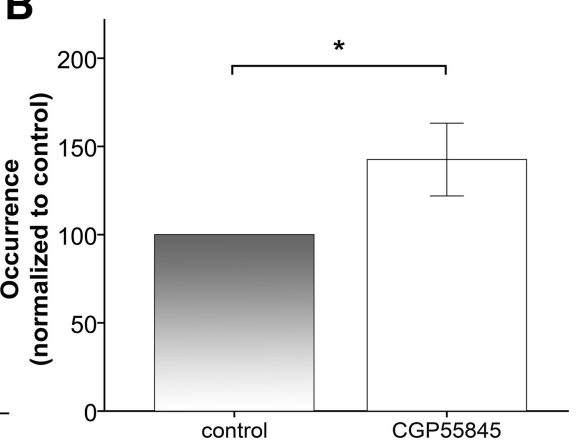

C

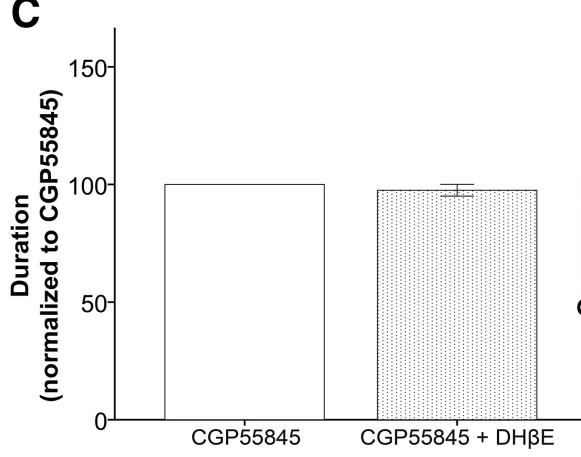

D
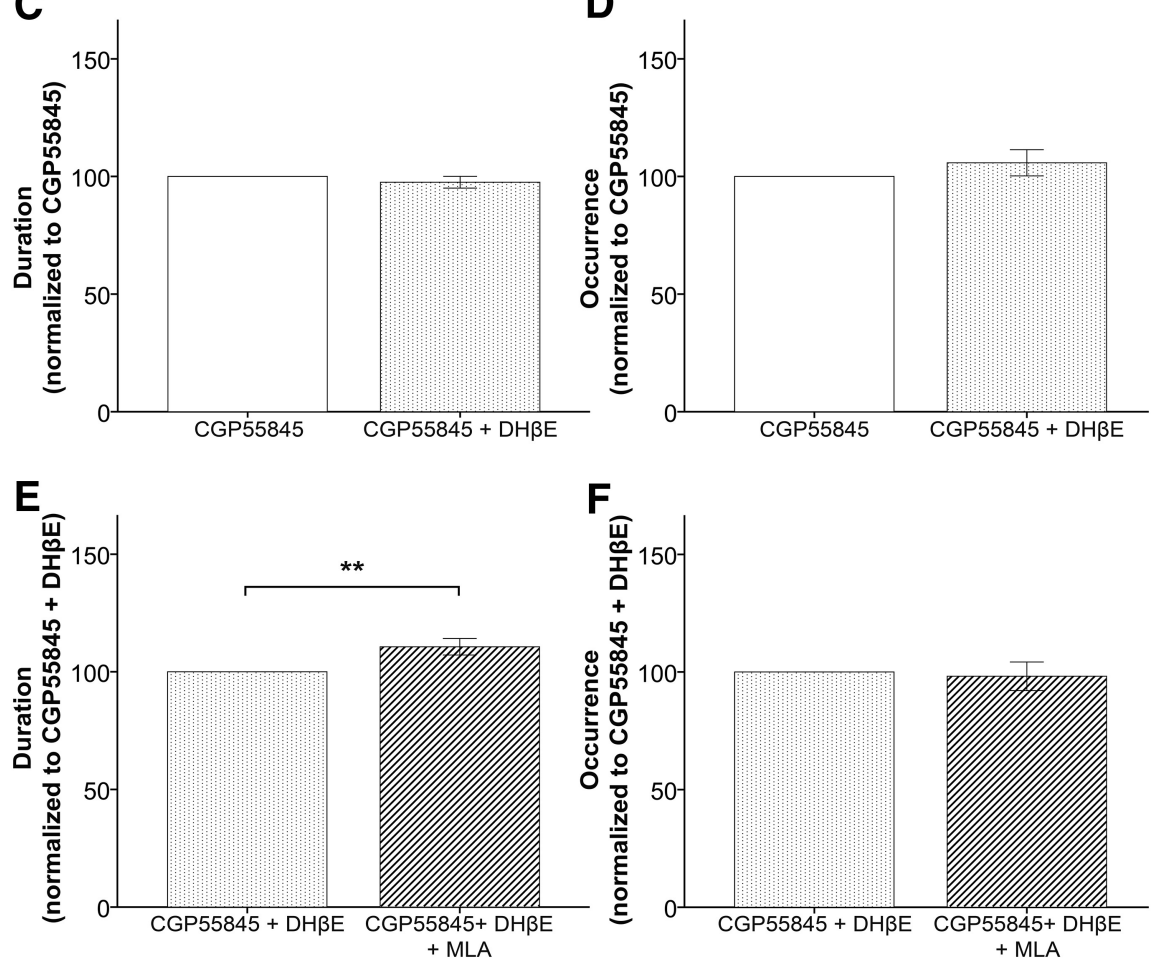

G

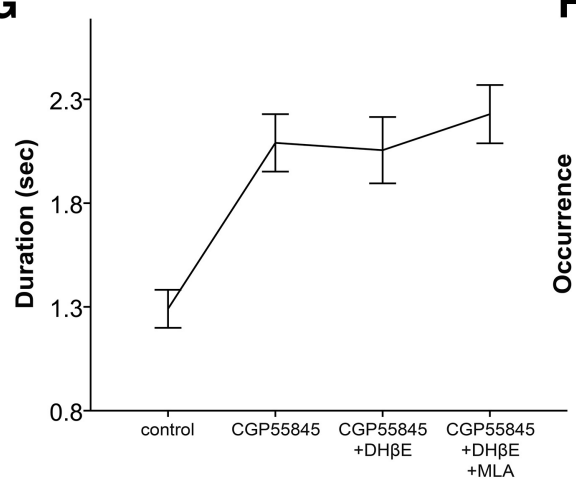

H

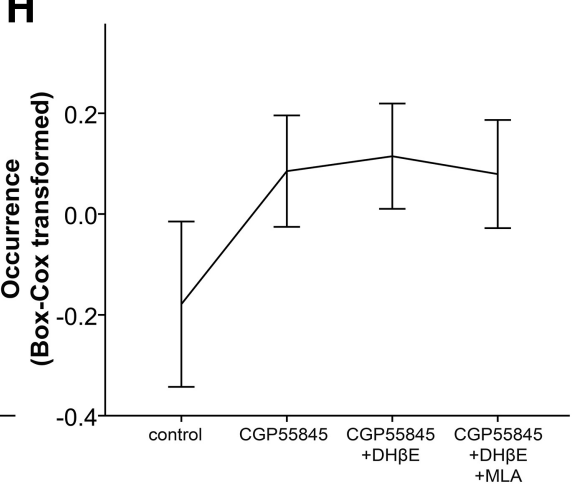

Figure 8. The effects of $\beta 2$-nAChRs on Up state activity are at least partly mediated through $G_{A B A}$ receptors. $A, B$, Application of the $G A B A_{B}$ receptor antagonist CGP55845 leads to increased Up state duration and occurrence (mean \pm SEM, data normalized to control values obtained in the absence of CGP55845). C, $D$, Subsequent application of DH $\beta E$ (in the presence of (GP55845) fails to produce the expected changes in Up state activity (mean \pm SEM, data normalized to values in the presence of CGP55845 before the addition of $\mathrm{DH} \beta \mathrm{E}$ ). $\boldsymbol{E}, \boldsymbol{F}$, Further application of MLA leads to the expected increase in Up state duration (mean $\pm \mathrm{SEM}$, data normalized to values obtained in the presence of both (GP55845 and DH $\beta$ E before the addition of MLA). $\boldsymbol{G}, \boldsymbol{H}$, Non-normalized values of Up state duration and occurrence, respectively, before and after the addition of CGP55845, DH $\beta$ E, and MLA (mean \pm SEM). These results are obtained in adult WT animals (one-way repeated-measures ANOVA, with pairwise comparisons post hoc tests, ${ }^{*} p<0.05,{ }^{* *} p<0.01$, and $\left.{ }^{* * *} p<0.001\right)$.

and/or synaptic elements that are preserved in the slice preparation. Possible sources of ACh could be the synaptic terminals originating in the cut fibers of the basal forebrain (Mesulam et al., 1983), which become stimulated by the intrinsic activity of the cortical tissue, and/or the sparse population of cholinergic cortical interneurons (Levey et al., 1984; Houser et al., 1985). Neurotransmitter release from neurons and severed axons in brain slices has been documented before (Zohar, 2001; Bandyopadhyay et al., 2006; von Engelhardt et al., 2007; Threlfell et al., 2012) but always after exogenous stimulation (electrical, pharmacological, or optogenetic). While such results reveal the existence of a release machinery, they do not necessarily reflect the physiological network operation. To our knowledge, our study is the first to report spontaneous release of a neuromodulator that can actively regulate synchronized network activity.

\section{Cholinergic modulation through $\beta 2$ - nAChRs and $\alpha 7$-nAChRs}

Although the main focus of the present study was the high-affinity $\beta 2$-cont aining nAChRs, our pharmacological analysis suggests distinct roles for low- and high-affinity nicotinic receptors, by revealing that $\alpha 7-\mathrm{nAChRs}$ affect only the termination of spontaneous Up states, while $\beta 2$-nAChRs also regulate their generation. The existence of a distinct mechanism of $\beta 2$-nAChR- and $\alpha 7$ nAChR-mediated signaling is further supported by their different response to $\mathrm{GABA}_{\mathrm{B}} \mathrm{R}$ blockade; in the presence of CGP55845 the effect of the former was blocked implying a shared common pathway, while the latter remained unaffected. $\mathrm{GABA}_{\mathrm{B}} \mathrm{R}$-mediated inhibition on spontaneous Down state transitions had been described in entorhinal cortical slices (Mann et al., 2009), but the mechanism that might engage this pathway remained unknown. Here we show that release of $\mathrm{ACh}$ can recruit $\mathrm{GABA}_{\mathrm{B}} \mathrm{R}$-mediated inhibition and promote termination of the Up state. We propose a model in which endogenously released ACh activates $\beta 2$-nAChRs on cortical interneurons (Alkondon and Albuquerque, 2004; Arroyo et al., 2012), leading to GABA release. This in turn activates $G A B A_{B}$ receptors, resulting in an attenuation of Up state activity. In contrast, the effect of $\alpha 7$-nAChRmediated activation occurs through a $\mathrm{GABA}_{\mathrm{B}}$-independent mechanism. Fur- 
ther experiments should test the validity of this proposed mechanism.

\section{Spontaneous Up states in the neocortex of $\beta 2^{-/-}$mice}

The differences we observed between WT and $\beta 2^{-1-}$ mice were eliminated in the presence of $\mathrm{DH} \beta \mathrm{E}$, suggesting that the greater Up state activity in mutant animals is directly linked to the lack of $\beta 2$-nAChR-mediated signaling and not an indirect effect of altered circuitry secondary to the genetic deletion. This was surprising, given that pyramidal cell microanatomy is altered in $\beta 2$ mutants (Ballesteros-Yáñez et al., 2010; Konsolaki and Skaliora, 2014). One possibility is that the increased dendritic branching and spine numbers observed in S1 neurons do not contribute to this type of network activity. Alternatively, and given the critical importance of these self-maintained depolarized states as a basic operation of cortical networks (Sanchez-Vives and McCormick, 2000; Shu et al., 2003; McCormick, 2005), we could speculate that such activity represents a robust signature of cortical dynamics that is under tight homeostatic regulation. Perhaps this robustness also accounts for the lack of an amplified or differential effect of age in $\beta 2^{-1-}$ mice, despite the accelerated aging phenotype previously reported in morphological and behavioral studies (Zoli et al., 1999; Konsolaki and Skaliora, 2014). This does not contradict the possibility that the structural modifications are reflected in other aspects of network function, but it suggests that spontaneous Up states may be tolerant to alterations in individual features of neuronal microanatomy.

\section{Nicotinic modulation of endogenous cortical activity}

Our results document a clear involvement of nicotinic signaling on cortical network dynamics and, thus, seem to contradict certain in vivo studies that report $\mathrm{mAChRs}$ as the sole mediators of the cholinergic modulation of Up state activity during EEG desynchronization (Metherate et al., 1992; Steriade et al., 1993). However, these studies have used stimulation of cholinergic inputs that consist of heterogeneous pathways, including reciprocal connections and GABAergic axons (Zaborszky et al., 2012), which may have masked a nicotinic contribution. In addition, they examined anesthetized animals, using urethane as anesthetic, a drug that has been shown to directly affect $\alpha 4 \beta 2$ nAChRs (Hara and Harris, 2002). Consistent with this inter pretation, and with our results, studies using naturally sleeping animals have shown that nicotine administration causes EEG desynchronization and behavioral arousal (Yamamoto and Domino, 1965; Armitage et al., 1969). Our finding of reduced Up state activity in the presence of nicotine further confirms the involvement of the nicotinic pathway in this type of network dynamics. Interestingly, the higher dose of the drug had no effect, as indeed had been reported by Favero et al. (2012). This may be attributable to a dose effect of desensitization of nAChRs (Dilger and Brett, 1990) and suggests a note of caution when interpreting data obtained with exogenous application of neuromodulators. Our results provide a potential synthesis of previously contradictory findings regarding the effect of nicotine on cortical dynamics and reveal that nAChR-mediated activity significantly modulates both the generation and the termination of cortical Up states.

\section{Implications for cortical network function}

The motivation for this study was to clarify the role of $\beta 2$ nAChR-mediated signaling on endogenous cortical dynamics. The coronal slice preparation offers the opportunity to examine the cortical microcircuit isolated from the thalamus, which is also modulated by nAChRs (Léna and Changeux, 1997) and without the confounding factors of anesthetics (Hara and Harris, 2002). The spontaneous release of ACh present in the slice further allowed us to investigate the intrinsic activation of nAChRs and not rely (exclusively) on exogenous application of arbitrarily defined nicotine concentrations, which would have acted nonselectively on all receptors. In this way, we were able to identify a distinct nicotinic contribution to the regulation of Up state activity that had been controversial in the literature and showed that this regulation occurs through both $\beta 2$-nAChRs and $\alpha 7$-nAChRs, but with different mechanisms. Moreover, we were able to provide a link to an already established regulatory pathway for Up states that is mediated through $\mathrm{GABA}_{\mathrm{B}} \mathrm{Rs}$. Our results favor a model according to which endogenous ACh directly stimulates cortical interneurons (containing $\beta 2$-nAChRs) rather than indirectly through nAChRs on presynaptic glutamatergic fibers (such as those arriving from the thalamus), because blocking $\beta 2$ receptors in the presence of a $\mathrm{GABA}_{B} \mathrm{R}$ antagonist failed to produce any effects.

Our findings provide a framework for targeted in vivo experiments to examine the significance of these results in the intact brain. Hasselmo and McGaughy (2004) proposed a model in which ACh acting through muscarinic receptors reduces intracortical processing, while simultaneously the activation of nicotinic receptors on glutamatergic thalamocortical neurons enhances the impact of afferent inputs. Based on our results, we speculate that (in addition to mAChRs) nAChRs may also be contributing to the modulation of intracortical processing. For instance, nAChR stimulation during slow-wave activity could affect internal processing by altering the rules for plasticity (Couey et al., 2007). In addition, a basal nicotinic tone may be required to persist even in the absence of active afferent inputs to keep the network in a responsive state, akin to the function of micro-arousals during NREM sleep (for review, see Halász et al., 2013).

\section{Concluding remarks}

Local cortical networks exhibit spontaneous network activity in the form of Up/Down states-a prominent feature of cortical activity during slow-wave sleep in vivo. The fact that this type of persistent activity can be sustained in the absence of subcortical or long-range inputs has fueled the proposal that Up/Down state activity in brain slices can serve as a model of the basic operation of the cortex and that the mechanisms that generate or modulate this type of activity may form the substrate for cognitive functions such as short-term memory, memory consolidation, or modulation of neuronal activity during attention (Sanchez-Vives and McCormick, 2000; Shu et al., 2003; Major and Tank, 2004; Yuste et al., 2005). Here we have revealed a direct modulatory role for the high-affinity nAChRs acting through $\mathrm{GABA}_{\mathrm{B}} \mathrm{Rs}$ in the regulation of this network phenomenon. Our results provide a framework that integrates previously contradictory results and suggests a new role for the nicotinic modulation of intrinsic persistent cortical activity under conditions of low ACh release, which could generate novel insights for therapeutic interventions of disorders related to abnormal patterns of cortical dynamics.

\section{References}

Alkondon M, Albuquerque EX (2004) The nicotinic acetylcholine receptor subtypes and their function in the hippocampus and cerebral cortex. Prog Brain Res 145:109-120. Medline

Alkondon M, Pereira EF, Eisenberg HM, Albuquerque EX (2000) Nicotinic receptor activation in human cerebral cortical interneurons: a mechanism for inhibition and disinhibition of neuronal networks. J Neurosci 20: 66-75. Medline 
Armitage AK, Hall GH, Sellers CM (1969) Effects of nicotine on electrocortical activity and acetylcholine release from the cat cerebral cortex. Br J Pharmacol 35:152-160. CrossRef Medline

Arroyo S, Bennett C, Aziz D, Brown SP, Hestrin S (2012) Prolonged disynaptic inhibition in the cortex mediated by slow, non- $\alpha 7$ nicotinic excitation of a specific subset of cortical interneurons. J Neurosci 32:3859-3864. CrossRef Medline

Ballesteros-Yáñez I, Benavides-Piccione R, Bourgeois JP, Changeux JP, DeFelipe J (2010) Alterations of cortical pyramidal neurons in mice lacking high-affinity nicotinic receptors. Proc Natl Acad Sci U S A 107:1156711572. CrossRef Medline

Bandyopadhyay S, Sutor B, Hablitz JJ (2006) Endogenous acetylcholine enhances synchronized interneuron activity in rat neocortex. J Neurophysiol 95:1908-1916. CrossRef Medline

Box GEP, Cox DR (1964) An analysis of transformation. J R Stat Soc Ser B Methodol 26:211-252.

Christophe E, Roebuck A, Staiger JF, Lavery DJ, Charpak S, Audinat E (2002) Two types of nicotinic receptors mediate an excitation of neocortical layer I interneurons. J Neurophysiol 88:1318-1327. Medline

Compte A, Reig R, Descalzo VF, Harvey MA, Puccini GD, Sanchez-Vives MV (2008) Spontaneous high-frequency $(10-80 \mathrm{~Hz})$ oscillations during up states in the cerebral cortex in vitro. J Neurosci 28:13828-13844. CrossRef Medline

Couey JJ, Meredith RM, Spijker S, Poorthuis RB, Smit AB, Brussaard AB, Mansvelder HD (2007) Distributed network actions by nicotine increase the threshold for spike-timing-dependent plasticity in prefrontal cortex. Neuron 54:73-87. CrossRef Medline

Dani JA, Bertrand D (2007) Nicotinic acetylcholine receptors and nicotinic cholinergic mechanisms of the central nervous system. Annu Rev Pharmacol Toxicol 47:699-729. CrossRef Medline

Dilger JP, Brett RS (1990) Direct measurement of the concentration- and time-dependent open probability of the nicotinic acetylcholine receptor channel. Biophys J 57:723-731. CrossRef Medline

Fanselow EE, Connors BW (2010) The roles of somatostatin-expressing (GIN) and fast-spiking inhibitory interneurons in UP-DOWN states of mouse neocortex. J Neurophysiol 104:596-606. CrossRef Medline

Favero M, Varghese G, Castro-Alamancos MA (2012) The state of somatosensory cortex during neuromodulation. J Neurophysiol 108:1010-1024. CrossRef Medline

Gulledge AT, Park SB, Kawaguchi Y, Stuart GJ (2007) Heterogeneity of phasic cholinergic signaling in neocortical neurons. J Neurophysiol 97:22152229. CrossRef Medline

Hájos N, Ellender TJ, Zemankovics R, Mann EO, Exley R, Cragg SJ, Freund TF, Paulsen O (2009) Maintaining network activity in submerged hippocampal slices: importance of oxygen supply. Eur J Neurosci 29:319327. CrossRef Medline

Halász P, Kelemen A, Szúcs A (2013) The role of NREM sleep microarousals in absence epilepsy and in nocturnal frontal lobe epilepsy. Epilepsy Res 107:9-19. CrossRef Medline

Hara K, Harris RA (2002) The anesthetic mechanism of urethane: the effects on neurotransmitter-gated ion channels. Anesth Analg 94:313-318, table of contents. CrossRef Medline

Harris RJ, Wieloch T, Symon L, Siesjö BK (1984) Cerebral extracellular calcium activity in severe hypoglycemia: relation to extracellular potassium and energy state. J Cereb Blood Flow Metab 4:187-193. CrossRef Medline

Hasselmo ME, McGaughy J (2004) High acetylcholine levels set circuit dynamics for attention and encoding and low acetylcholine levels set dynamics for consolidation. Prog Brain Res 145:207-231. Medline

Houser CR, Crawford GD, Salvaterra PM, Vaughn JE (1985) Immunocytochemical localization of choline acetyltransferase in rat cerebral cortex: a study of cholinergic neurons and synapses. J Comp Neurol 234:17-34. CrossRef Medline

Ivanov A, Zilberter Y (2011) Critical state of energy metabolism in brain slices: the principal role of oxygen delivery and energy substrates in shaping neuronal activity. Front Neuroenergetics 3:9. CrossRef Medline

Jones HC, Keep RF (1988) Brain fluid calcium concentration and response to acute hypercalcaemia during development in the rat. J Physiol 402: 579-593. CrossRef Medline

Klink R, de Kerchove d' Exaerde A, Zoli M, Changeux JP (2001) Molecular and physiological diversity of nicotinic acetylcholine receptors in the midbrain dopaminergic nuclei. J Neurosci 21:1452-1463. Medline

Konsolaki E, Skaliora I (2014) Premature aging phenotype in mice lacking high-affinity nicotinic receptors: region-specific changes in layer $\mathrm{V}$ pyramidal cell morphology. Cereb Cortex Advance online publication. Retrieved February 18, 2014. doi: 10.1093/cercor/bhu019. CrossRef

Lambe EK, Picciotto MR, Aghajanian GK (2003) Nicotine induces glutamate release from thalamocortical terminals in prefrontal cortex. Neuropsychopharmacology 28:216-225. CrossRef Medline

Léna C, Changeux JP (1997) Role of $\mathrm{Ca}^{2+}$ ions in nicotinic facilitation of GABA release in mouse thalamus. J Neurosci 17:576-585. Medline

Léna C, Popa D, Grailhe R, Escourrou P, Changeux JP, Adrien J (2004) $\beta 2$-containing nicotinic receptors contribute to the organization of sleep and regulate putative micro-arousals in mice. J Neurosci 24:5711-5718. CrossRef Medline

Levey AI, Wainer BH, Rye DB, Mufson EJ, Mesulam MM (1984) Choline acetyltransferase-immunoreactive neurons intrinsic to rodent cortex and distinction from acetylcholinesterase-positive neurons. Neuroscience 13: 341-353. CrossRef Medline

Major G, Tank D (2004) Persistent neural activity: prevalence and mechanisms. Curr Opin Neurobiol 14:675-684. CrossRef Medline

Mann EO, Kohl MM, Paulsen O (2009) Distinct roles of GABA(A) and GABA(B) receptors in balancing and terminating persistent cortical activity. J Neurosci 29:7513-7518. CrossRef Medline

Mansvelder HD, van Aerde KI, Couey JJ, Brussaard AB (2006) Nicotinic modulation of neuronal networks: from receptors to cognition. Psychopharmacology 184:292-305. CrossRef Medline

McCormick DA (2005) Neuronal networks: flip-flops in the brain. Curr Biol 15:R294-R296. CrossRef Medline

Mesulam MM, Mufson EJ, Wainer BH, Levey AI (1983) Central cholinergic pathways in the rat: an overview based on an alternative nomenclature (Ch1-Ch6). Neuroscience 10:1185-1201. CrossRef Medline

Metherate R, Cox CL, Ashe JH (1992) Cellular bases of neocortical activation: modulation of neural oscillations by the nucleus basalis and endogenous acetylcholine. J Neurosci 12:4701-4711. Medline

Mogg AJ, Whiteaker P, McIntosh JM, Marks M, Collins AC, Wonnacott S (2002) Methyllycaconitine is a potent antagonist of $\alpha$-conotoxin-MIIsensitive presynaptic nicotinic acetylcholine receptors in rat striatum. J Pharmacol Exp Ther 302:197-204. CrossRef Medline

Oppenheim AV, Schafer RW, Buck JR (1999) Discrete-time signal processing, ed 2. Upper Saddle River, NJ: Prentice Hall.

Picciotto MR, Zoli M (2002) Nicotinic receptors in aging and dementia. J Neurobiol 53:641-655. CrossRef Medline

Poorthuis RB, Bloem B, Schak B, Wester J, de Kock CP, Mansvelder HD (2013) Layer-specific modulation of the prefrontal cortex by nicotinic acetylcholine receptors. Cereb Cortex 23:148-161. CrossRef Medline

Porter JT, Cauli B, Tsuzuki K, Lambolez B, Rossier J, Audinat E (1999) Selective excitation of subtypes of neocortical interneurons by nicotinic receptors. J Neurosci 19:5228-5235. Medline

Potter AS, Newhouse PA (2004) Effects of acute nicotine administration on behavioral inhibition in adolescents with attention-deficit/hyperactivity disorder. Psychopharmacology 176:183-194. CrossRef Medline

Rigas P, Castro-Alamancos MA (2007) Thalamocortical Up states: differential effects of intrinsic and extrinsic cortical inputs on persistent activity. J Neurosci 27:4261-4272. CrossRef Medline

Rigas P, Sigalas C, Skaliora I (2011) Developmental regulation of spontaneous network activity in mouse cortical slices. Neurosci Lett 500, Supplement:e40. CrossRef

Salin-Pascual RJ, Moro-Lopez ML, Gonzalez-Sanchez H, Blanco-Centurion C (1999) Changes in sleep after acute and repeated administration of nicotine in the rat. Psychopharmacology 145:133-138. CrossRef Medline

Sanchez-Vives MV, McCormick DA (2000) Cellular and network mechanisms of rhythmic recurrent activity in neocortex. Nat Neurosci 3:10271034. CrossRef Medline

Sanchez-Vives MV, Descalzo VF, Reig R, Figueroa NA, Compte A, Gallego R (2008) Rhythmic spontaneous activity in the piriform cortex. Cereb Cortex 18:1179-1192. CrossRef Medline

Shu Y, Hasenstaub A, McCormick DA (2003) Turning on and off recurrent balanced cortical activity. Nature 423:288-293. CrossRef Medline

Steriade M, Amzica F, Nuñez A (1993) Cholinergic and noradrenergic modulation of the slow (approximately $0.3 \mathrm{~Hz}$ ) oscillation in neocortical cells. J Neurophysiol 70:1385-1400. Medline

Threlfell S, Lalic T, Platt NJ, Jennings KA, Deisseroth K, Cragg SJ (2012) Striatal dopamine release is triggered by synchronized activity in cholinergic interneurons. Neuron 75:58-64. CrossRef Medline 
Timofeev I, Grenier F, Steriade M (2001) Disfacilitation and active inhibition in the neocortex during the natural sleep-wake cycle: an intracellular study. Proc Natl Acad Sci U S A 98:1924-1929. CrossRef Medline

Toth A, Hajnik T, Detari L (2012) Cholinergic modulation of slow cortical rhythm in urethane-anesthetized rats. Brain Res Bull 87:117-129. CrossRef Medline

von Engelhardt J, Eliava M, Meyer AH, Rozov A, Monyer H (2007) Functional characterization of intrinsic cholinergic interneurons in the cortex. J Neurosci 27:5633-5642. CrossRef Medline

Yamamoto KI, Domino EF (1965) Nicotine-induced EEG and behavioral arousal. Int J Neuropharmacol 4:359-373. CrossRef Medline

Yuste R, MacLean JN, Smith J, Lansner A (2005) The cortex as a central pattern generator. Nat Rev Neurosci 6:477-483. CrossRef Medline
Zaborszky L, van den Pol A, Gyengesi E (2012) The basal forebrain cholinergic projection system in mice. In: The mouse nervous system (Watson C, Paxinos G, Puelles L, eds), pp 684-718. Amsterdam: ElsevierAcademic Press.

Zohar O (2001) Electrophysiological and ultrastructural changes in severed motor axons of the crayfish. Neurosci Res 41:151-159. CrossRef Medline

Zoli M, Léna C, Picciotto MR, Changeux JP (1998) Identification of four classes of brain nicotinic receptors using $\beta 2$ mutant mice. J Neurosci 18:4461-4472. Medline

Zoli M, Picciotto MR, Ferrari R, Cocchi D, Changeux JP (1999) Increased neurodegeneration during ageing in mice lacking high-affinity nicotine receptors. EMBO J 18:1235-1244. CrossRef Medline 